y admiración, aporta tanta enseñanza, consuelo y confianza juntas que no hay página con frase que no encierre una imagen, una idea, una ilusión, una dosis de ternura y ambición de libertad.

\title{
Campio Carpio
}

Luis Monguió, César Vallejo (1892-1938). Vida y obra. Bibliografía. Antologia.-New York, Hispanic Institute in the United States, 1952. Rústica, 144 pp. Precio: $\$ 2.00$.

Como es usual en las monografías de Autores modernos publicadas por el Instituto Hispánico de Nueva York, este estudio dedicado a César Vallejo se divide en las cuatro partes que el título indica.

El profesor Monguió comienza la biografía del poeta peruano con unas páginas que dedica a Santiago de Chuco — pueblecito del Perú-, en lógica creencia de que el artista tiene fuertes raíces en su tierra y que ésta ha influído en él de un modo básico y trascendental. $Y$ no solamente lo emplaza y lo describe sino que se remonta a los tiempos de su fundación, a los dias de la Colonia virreinal, y luego avanza hasta fines del siglo XIx -en cuya última década nació su biografiado- para ocuparse de su población, de sus productos y de otros aspectos notables. Abundantes textos antiguos y modernos apoyan y comprueban cada uno de los datos que contribuyen a esta completa reconstrucción geográfica e histórica.

La fecha de nacimiento, incierta hasta el momento, ocupa también la atención del profesor Monguió, el cual, después de laboriosas investigaciones y escrupuloso cotejo de documentos, fija con seguridad el año 1892 y señala como día casi probable el 15 ó 16 de marzo.

La evocación de la casa paterna, luego, y de la familia del poeta termina por precisar el mundo en que se desarrolló la infancia de César Vallejo. Las escasas referencias que de ella se poseen, han obligado al biógrafo a presentarla de un modo somero pero suficiente. Viene después la adolescencia: aquí se ocupa de la educación secundaria recibida por el poeta y de sus primeros empleos. Monguió apunta, por primera vez en su biografía, que César Vallejo empezó a experimentar "problemas económicos personales que luego le atenazaron toda su vida". Nos 
advierte, además, que dichos empleos permitieron al poeta observar bien de cerca las condiciones del campesino peruano.

Sabemos que César Vallejo estudió en la Universidad de Trujillo, graduándose de Bachiller en Letras en 1915, después de presentar como tesis un estudio sobre El romanticismo en la poesía castellana. Aun prolongó sus estudios hasta 1918, ganándose la vida durante estos años como preceptor en dos escuelas. Monguió reseña los rasgos más salientes de César Vallejo como maestro: poco puntual, distraído, benévolo, con una pronunciación de hombre de la Sierra... Y, en Trujillo, una vida de bohemia le arrastró fatalmente a expresarse en versos, apareciendo los primeros en 1913 en un boletín escolar. Los siguientes vieron la luz en una revista y en periódicos de aquella ciudad, cuyo ambiente y círculos literarios son descritos por Monguió para situar en él y en ellos al joven poeta. Estos poemas recibieron elogios, críticas adversas y hasta ridiculas burlas del lado conservador. Para los críticos "pacatos", César Vallejo era un irreverente que escribía "mamarrachos". Pero los ataques pasaron de límite y el joven poeta fué víctima de un atentado nocturno en que estuvo a punto de perder su melena...

Llega 1918 y Vallejo aparece en Lima, donde es saludado por un artículo de Valdelomar que anunciaba "el nacimiento de un gran poeta".

Monguió sigue la vida de éste, reconstruyéndola cabalmente: César Vallejo se presenta ante el lector con relieve y bulto de persona viva, pues la verificación de las noticias biográficas - muy abundantes y exactas- está dada en notas al pie de cada página y así no interrumpe el ritmo vital y el interés humano que su figura emana.

A fines de 1918 su primer libro de poemas - Los beraldos negrosvió la luz. Monguió lamenta no haber podido averiguar - a través de periódicos y revistas de la época- la acogida que tuvo la obra entre sus contemporáneos inmediatos. No obstante, algunas referencias encontradas le hacen suponer que el libro fué recibido con frialdad e indiferencia.

En Lima también cursó estudios de Letras y Derecho. En 1920 perdió su empleo de maestro y decidió marchar a París. Pero, antes de partir, intervino en sucesos políticos que ocurrieron en su pueblo natal $y$ sufrió persecución y encarcelamiento. Monguió refiere estos hechos - dolorosa etapa en la vida de su biografiado- con bastantes detalles. Estos acontecimientos retardaron el proyectado viaje del poeta, el cual, ya en libertad, ganó un premio con un cuento $y$, con el dinero de la recom- 
pensa, editó su segundo libro de poemas: Trilce (1922). Según parece, el libro cayó en el vacío y su autor, descorazonado, decidió partir a Francia definitivamente. Monguió declara no conocer los medios económicos con que el poeta se lanzó a esta gran aventura, a mediados de 1923. Lo cierto es que luchó con la miseria en la gran capital, viviendo en el Barrio Latino años de bohemia y desvalimiento. Pero en 1925, al crearse el Bureau des Grands Journaux Latino-Américains, Vallejo trabajó en la nueva empresa mejorando así su crítica situación. Monguió supone que, a fines de este año, Vallejo debió ir a España con una beca, a la cual renunció pronto "por no poder soportar el ambiente del gobierno de Primo de Rivera", regresando a París casi inmediatamente.

Vallejo sufrió por entonces una profunda crisis intelectual y filosófica - bien estudiada y fundamentada por su biógrafo- que terminó por llevarle a Rusia a fines de 1929. Monguió opina que los dos viajes que hizo a aquel país y el encarcelamiento en el Perú, fueron algo crucial en la vida y obra del poeta. Poco después, Vallejo marchó a Madrid, en donde apareció la segunda edición de Trilce (1930) con un prólogonoticia de José Bergamín y con un poema-salutación de Gerardo Diego.

Expulsado de Francia a causa de su filiación política, trabajó en varios periódicos madrileños. $\mathrm{Y}$ en Madrid escribió su novela El Tungsteno que se publicó en 1931. En este mismo año apareció un volumen que contenía sus artículos sobre Rusia, con el título de Rusia en 1931, Reflexiones sobre el Kremlin, bien apreciado por la crítica, según parece, pues fué recomendado en el fallo de la Asociación del Mejor Libro del Mes.

Cuando se proclamó la República el 14 de abril de 1931, Vallejo "estaba dedicado en Madrid a una intensa actividad política". Vallejo, además, frecuentaba los círculos intelectuales madrileños y trataba a Rafael Alberti, a Garcia Lorca, a Pedro Salinas...

Según se cree, Vallejo regresó a Francia a principios de 1933. Monguió dice: "Desde su regreso a París quién sabe cómo y de qué vivió César Vallejo..." Sin embbargo, es casi seguro que llevaba una vida difícil y quizá miserable. Pero su labor literaria no se interrumpió: escribió varios dramas, una comedia y preparó dos volúmenes de estudios y ensayos, obras casi todas inéditas hasta la fecha.

Al estallar la insurrección franquista, en 1936, Vallejo se incorporó con todas sus fuerzas - las últimas que le quedaban- a la defensa del pueblo español, escribiendo generosamente artículos y más artículos. 
Por último, "rompe de nuevo en poesía", componiendo su libro Poemas bumanos, una serie del cual se relaciona con la tragedia española: "España, aparta de mí ese cáliz".

Monguió acaba la vida de César. Vallejo, narrando patéticamente su enfermedad y muerte.

La segunda parte de la monografía está dedicada al estudio de la obra de César Vallejo. Monguió examina en ella cada uno de sus libros, los cuales quedan perfectamente caracterizados; sobre todo, en cuanto a sus rasgos esenciales, mediante un análisis de su estructura y composición, influencias, temática, estilo, etc. Observa un crecimiento poético entre su primer y segundo libro, siendo este último una obra autónoma e independiente, liberado su autor del modernismo: "poesía básicamente humana, envuelta en una manera sintética como la de las escuelas vanguardistas, en un alarde de liberación con respecto a la retórica y poética de la generación anterior". En cuanto a las obras en prosa de César Vallejo, también son enjuiciadas en sus aspectos más sobresalientes. Los Poemas bumanos acaso merecen el examen más apasionado $-\mathrm{y}$ más sentido- de Monguió, tal vez porque el tema de España juega en él una parte importantísima, quizá porque el alma queda en ellos más "al desnudo", o porque este libro es "más que piedad: es amor, es solidaridad y es acción".

Amado es aquel que tiene chinches, el que lleva zapato roto bajo la lluvia, el que vela el cadáver de un pan con dos cerillas...

(¡Sólo puede decir esto el poeta que ha sufrido un hambre trágica!)

Una completa bibliografía y uan adecuada y eficaz antología cierran este libro de Luis Monguió, estudio que es menester considerar capital para el entendimiento de la vida y la obra de César Vallejo, poeta peruano "cuyo dolor subjetivo se identifica con el de la raza indígena $y$ se expresa con novedad y sintetismo", en opinión de Federico de Onís que le incluyó en su vasto monumento antológico de 1934.

Concha Zardoya,

Tulane University. 